\title{
Studies of the grounding-line location on Ice Streams $D$ and E, Antarctica
}

\author{
Robert W. Jacobel, Audrey E. Robinson, \\ Department of Physics, St. Olaf College, Northfield, MN 55057, U.S.A. \\ ROBERT A. BINDSCHADLER \\ Code 971, NASA/Goddard Space Flight Center, Greenbell, MD 20771, U.S.A.
}

\begin{abstract}
Landsat Thematic Mapper (TM) images were used prior to the 1991-92 field season to infer the position of the grounding line at the mouths of Ice Streams D and E, West Antarctica. Our field plan for mass-balance studies was based on this determination, and thus the imagery played a central role in both the scientific and logistics planning. A radar profile along the flow direction was made across the inferred grounding line at one location, and ice-thickness measurements together with surface surveying enable us to compare the hydrostatic surface and the actual topography to determine the point at which the ice becomes grounded. The profile transits from floating to grounded ice at the same location as the grounding line inferred from the imagery. Changes in the radar-echo strength also occur at this location, giving further support to this interpretation. Tilt studies of the ice flexure caused by tidal variations at locations on either side of this grounding point give additional evidence that grounding is occurring close by. The combination of these three measurements therefore confirms the grounding-line location derived from the satellite imagery and supports the use of this technique to determine grounding.
\end{abstract}

\section{INTRODUGTION}

Grounding-line locations of the ice streams in Antarctica have been determined by a number of methods, among them aerial photography, airborne radar, surface-tilt measurements, surveys of the surface slope and visual inspection of strand cracks. As a part of the ongoing studies of the ice streams in West Antarctica Whillans and Alley, 1991), we are in the process of making measurements of the mass balance of Ice Streams D and $\mathrm{E}$ which require a determination of the velocity and ice thickness just downstream of the grounding line. In preparation for this field work, we were able to use Landsat Thematic Mapper (TM) imagery to examine the region of the proposed study because these two ice streams lie within the field of view of the satellite. From these images, we inferred the position of the grounding line and developed logistical plans so that our survey and groundbased radar lines traversed the ice streams just downstream of grounding. Preliminary reports on the massbalance measurements and an investigation of some of the topographic features seen in the imagery have been presented in Jacobel and Bindschadler (1993). We report here on studies done with radar and tilt measurcments which confirm the grounding-line location determined from the imagery, and hence support the use of this technique more generally.

Figure 1 is a mosaic of TM images showing the area of the mouths of Ice Streams D and E. The S line through the base camps labeled "Washington" and "Baltimore" is transverse to the flow, and is the gate we are using for the mass-flux calculation. Ice-thickness measurements along this line have been completed (Jacobel and others, 1992) and velocity stakes are currently in place and awaiting resurvey in the 1993-94 field season. The short-wavelength shading patterns in the image are produced by surface topography illuminated at low Sun angle from the northeast, or upper left in the figure. This topographic pattern should not be confused with the more regional light-dark contrast in the image which results from the higher surface albedo of newly deposited snow, such as the area surrounding the Washington base camp. In the figure, we also indicate the position of the grounding line (dotted) in this region, inferred from topographic features in the ice streams and the absence of these as the ice becomes afloat.

Bumps in the surface topography (revealed by shading in the image) in the mouths of the ice streams are zones of grounded ice where the excess ice thickness is supported by normal forces from the bed. One such grounded zone can be seen just upstream of the Baltimore camp in Figure 1. A more subtle bump, also indicating grounding, is located just north (left) of the Washington camp, and is crossed by the lines labeled $\mathrm{B}$ and $\mathrm{C}$ in the figure. $\mathrm{A}$ radar profile was made along the $B$ line to obtain ice thickness and to look for changes in the echo strength associated with grounding. In addition, tiltmeters were placed both at Washington base camp and at the summit of the bump on the $\mathrm{B}$ line. 


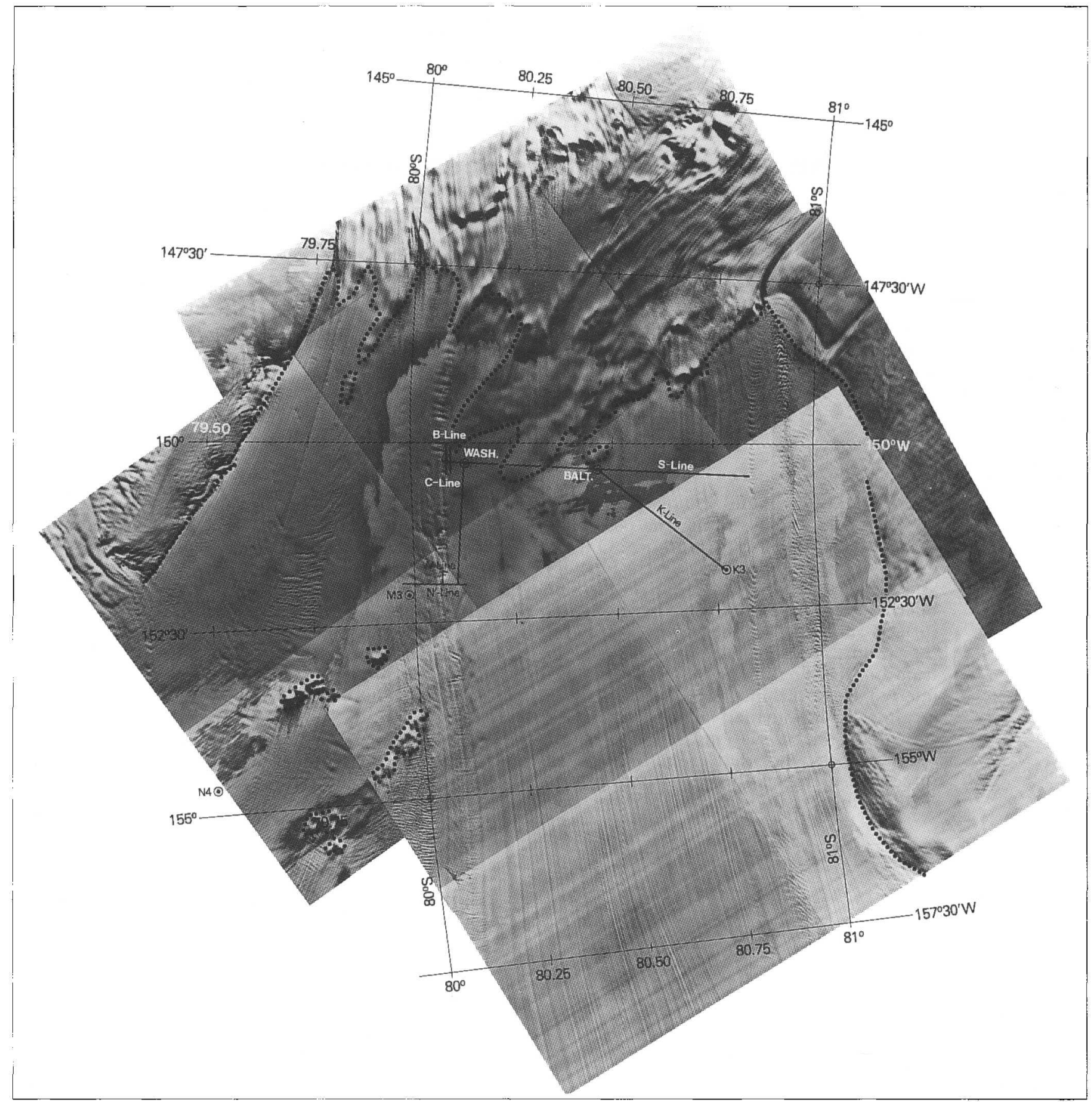

Fig. 1. A mosaic of Landsal TM images of the confluence of Ite Streams D and E near the grounding area. Camp locations and profile lines are indicated as well as the RIGGS stations K3 and M3. The position of the grounding line (dotted) inferred from topographic features in the imagery is also shown.

\section{RADAR STUDIES}

The radar system used was an impulse radar operating at a center frequency of $2 \mathrm{MHz}$, as described by Jacobel and others (1988). Modifications since that report include a PCbased data-acquisition system, allowing higher data rates, stacking to eliminate noise and the use of profile displays in the field. The system with operator was towed on a Nansen sled by a Skidoo moving typically at $4 \mathrm{~m} \mathrm{~s}^{-1}$ and data were acquired at a density of one wave form every $10 \mathrm{~m}$.

Figure 2 a shows the results of radar ice thickness and surface-leveling measurements along the $B$ line. An approximation to the hydrostatic surface (obtained from 0.9 times the ice thickness) is indicated by the dashed line in this figure, and has been adjusted so that ice at the downstream end is floating. Floating ice here is justified by similar radar and leveling measurements on the transverse S line (Jacobel and others, 1992) which crosses the B line at $\mathrm{km} 2$ and shows the ice is in hydrostatic equilibrium throughout this area. Grounding on the B line occurs between $\mathrm{km} 2$ and 3, and the bump itself is about $7 \mathrm{~m}$ above hydrostatic. This means the ice thickness here would need to be approximately $70 \mathrm{~m}$ greater to support the additional mass of the bump, were it not for normal forces at the bed provided by grounding.

We also expect a decrease in the radar-echo strength as the thickness of sea water between the ice and the bed approaches zero. The magnitude of this expected change is difficult to calculate because the electromagnetic boundary condition does not change abruptly from 

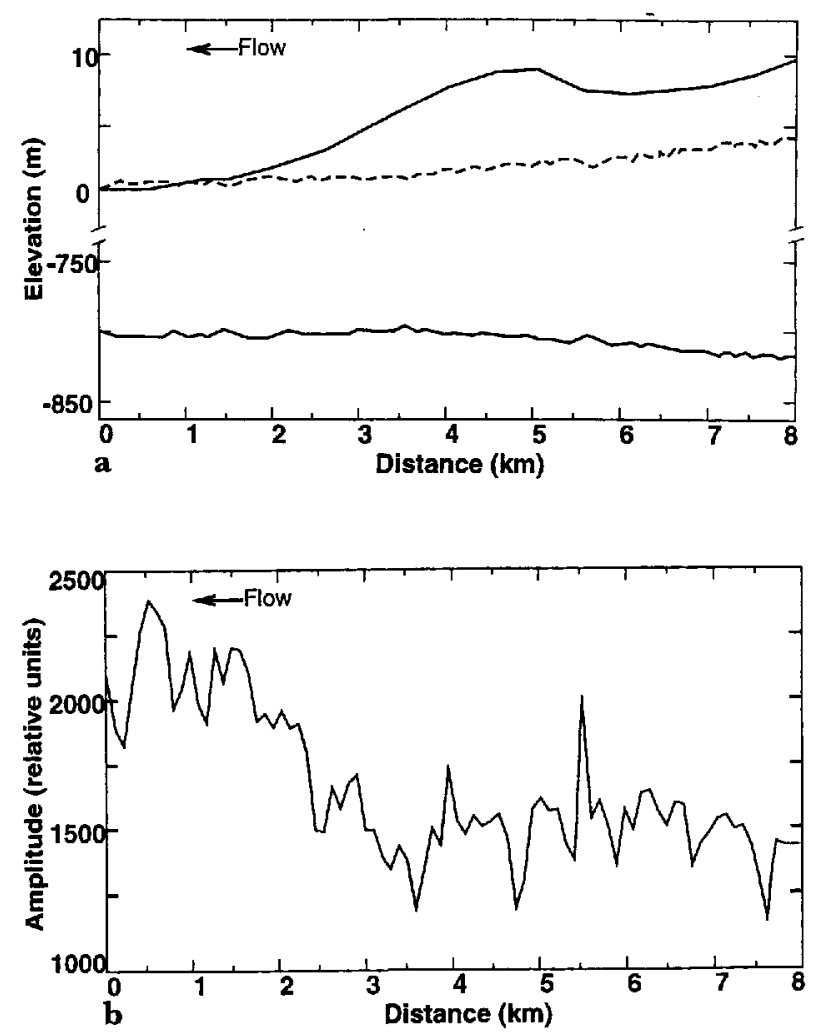

Fig. 2. a. Surveyed surface topography and bed depth determined from radar sounding along the " $B$ line". The dashed line indicates the hydrostatic surface adjusted so that the ice at the downstream end is floating. The ice surface upstream from this region rises up to $7 \mathrm{~m}$ above the hydrostatic level, indicating areas of grounding. $b$. Radar echo-return amplitude of the ice bottom along the same line.

water to bedrock. Instead, a thin layer of water is quite likely present even though the weight of the ice is supported by the bed. The wavelength of our $2 \mathrm{MHz}$ impulse radar is several tens of meters in ice, and changes in the echo strength at the lower ice boundary depend on the water-layer thickness relative to this wavelength in a complicated way (Jacobel and Anderson, 1987). Nevertheless, we have measured changes in the amplitude of the echo from the ice bottom along the $B$ line and the results are shown in Figure 2b. On average, the signal amplitude decreases by about $30 \%$ between $\mathrm{km} 2$ and $\mathrm{km} 3$, corresponding to the same grounding point indicated by the ice-thickness data in Figure $2 \mathrm{a}$.

\section{TILT MEASUREMENTS}

The purpose of tiltmeters placed at Washington base camp and at a site near the summit of the bump on the B line was to detect possible tilting caused by tidal variation at locations proximate to a point of grounding. Well downstream of grounding, the Ross Ice Shelf rises and falls with the tides but does not tilt, while upstream of this point there is no tidal motion. Thus, tilting with tidal periodicities will be an indication of proximity to the grounding line. At each site, tilting was recorded along two orthogonal axes and these data are shown in Figure 3. The orientation of the axes was chosen to

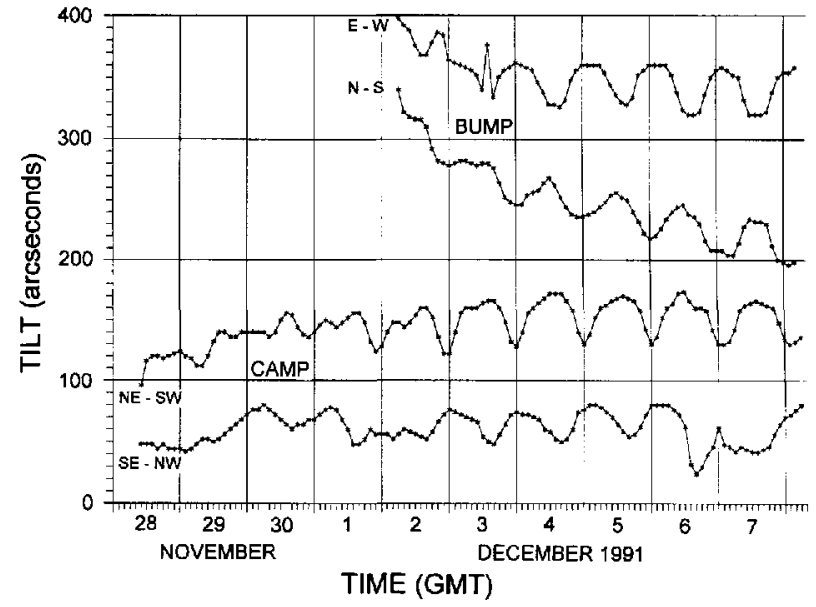

Fig. 3. Tiltmeter records from the two sites discussed in the text. Each meter records till along two axes labeled in the figure. The origin of the vertical scale for each time-series is arbitrary, so that all four data sets can be displayed on the same plot. A strong diurnal signal is evident and is superposed on transients as the instruments sellle.

maximize the tilt measured at each location based on our best guess of the nearest point of grounding, and is indicated in the figure. An approximately diurnal signal is evident in all four records superposed on transients due to settling of the instruments. In the figure, the time-series are each plotted with an arbitrary origin for the vertical scale so that they can be displayed together. The signal amplitudes in each case are therefore very similar. Some tilt just above the grounding point is to be expected, according to model results of Smith (1991) based on data from Doake Ice Rumples which show that the grounding point and the limit of flexing do not necessarily coincide.

Each of these time-series was Fourier-analyzed for frequency content, and typical power-spectra results are shown in Figure 4. The records for tilt along both axes at Washington camp (on floating ice) show a diurnal as well as a semi-diurnal periodicity, with the $12 \mathrm{~h}$ amplitude approximately half that at $24 \mathrm{~h}$. At the bump site (just above the grounding point), only the diurnal signal is present. Some rectification may also be present in the records, especially at Washington camp site, possibly because the ice flexes less at low tide when the buoyancy force plays less of a role in supporting the ice.

While it might be expected that the air temperature could have a diurnal component, we are confident that, for several reasons, the signal in Figure 3 is duc to tidal variation. The first is that both tiltmeters were buried several meters below the surface and covered to isolate them from solar radiation. The second is that observed air temperature in this location varied primarily with tropospheric pressure systems (regional weather patterns), not with time of day.

Further confirmation that this signal is indeed tidal comes from model studies of the Ross Sea tides. Numerical simulations of the Ross Sea tides have been carricd out by MacAyeal (1984), which have good firstorder agreement with tidal-amplitude observations made at a number of sites around the Ross Ice Shelf. The model shows that, in the region of the Ice Stream $D / E$ 
BUMP E-W

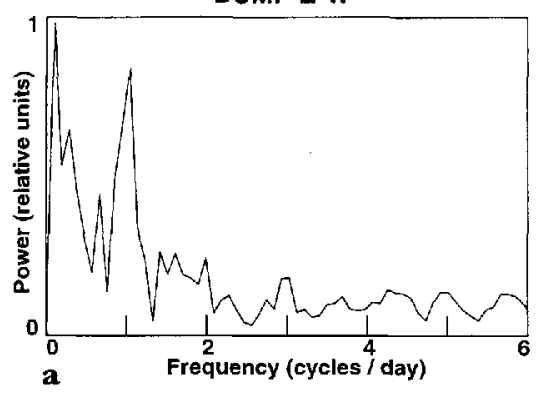

WASH NE-SW

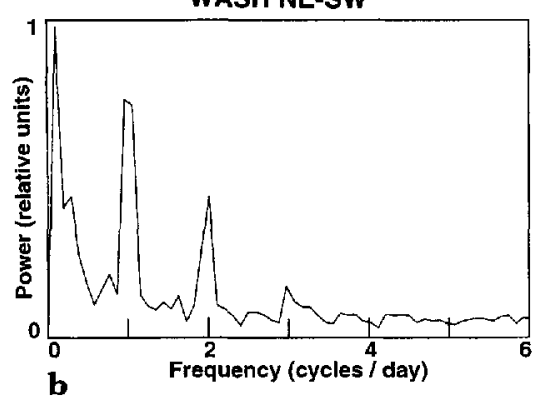

Fig. 4. Power spectra from two of the records above. a. Washington camp (on floating ice), showing both diurnal and semi-diurnal tidal phases. $b$. Summit of the bump line (just above the grounding poinl), showing only a signal from the larger-amplitude diumal tidal phase. Vertical power scale is linear.

embayment, diurnal tidal variations are expected to have approximately twice the amplitude of semi-diurnal tides (figs 5 and 6 of MacAyeal (1984)), in good agreement with our findings at Washington camp site.

Studies of the grounding line using extensive arrays of tiltmeters near Doake Ice Rumples on the Ronne Ice Shclf show similar results (Smith, 1991). Tilt signals of greater than $100 \mu \mathrm{rad}$ (20 arcsec) have been observed for several kilometers downstream of the grounding line, while the tidal signal is extinguished morc rapidly within the first $2 \mathrm{~km}$ on the grounded ice. Some rectification of the signal is evident upstream of the grounding lines, although unlike our data, both tidal phases are still present. The more nearly equal (and much larger) diurnal and semi-diurnal tidal amplitudes near their site may account for this difference. While our short-term study with only two tiltmeters is far less extensive, the results are similar and, together with the other evidence, give us confidence we are observing flexure of the ice due to tides beneath the Ross Ice Shelf and thus confirm the proximity of the grounding line.

\section{DISCUSSION AND CONGLUSIONS}

In the present study, grounding-line positions inferred from radar ice-thickness measurements, echo amplitudes and tidal flexure all agree and confirm observations of the location of grounded ice made from Landsat TM imagery. Spatial coverage of the latter is far more extensive and, when available, may be the best means of inferring grounding. This is especially true in areas where ocean-floor topography is varied as in the present case, or where it has a considerable slope. The grounding line on Ice Streams D and E is irregular with deep embayments and is revealed primarily by the surface expression of an irregular bed, which may possibly result from a lack of the thick till deposits seen in other ice streams. A contrasting case is the grounding region of Ice Stream B which is an extensive ice plain with little topographic relief and a surface slope less than 0.001 . Nevertheless, the grounding line can still be seen in SPOT imagery of the area (Bindschadler, 1993). In this case, the trace is more regular and continuous which helps reveal grounding even though the topographic relief is very low. Thus satellite imagery can be used under a range of conditions to infer grounding.

The position of ice-stream grounding lines is a critical measure of the response of the West Antarctic ice sheet to environmental change. Regardless of the exact mechanics of a marine ice-sheet instability or the precise role played by the ice streams, changes in their grounding-line positions are a sensitive indicator of mass-balance changes in the West Antarctic ice sheet. Monitoring groundingline positions and their changes over time will therefore be an important component of glaciological studies of this dynamic region. The availability of satellite imagery can greatly facilitate these studies and has been shown here to be a reliable indicator of grounding-line position.

\section{ACKNOWLEDGEMENTS}

We should like to express our thanks to P. Vornberger and T. Scambos of NASA-Goddard for invaluable collaboration and assistance with the field work. We thank the U.S. National Science Foundation which supported this work with grant DPP-9104417 to St. Olaf College, and grant DPP-9018127 to NASA-Goddard Space Flight Center.

\section{REFERENCES}

Bindschadler, R.A. 1993. Siple Coast project research of Crary Ice Rise and the mouths of Ice Streams B and C, West Antarctica: review and new perspectives. 7. Glaciol., 39:133), 538-552.

Jacobel, R.W. and S. K. Anderson. 1987. Interpretation of radio-echo returns from internal water bodies in Variegated Glacier, Alaska, U.S.A. 7. Glaciol., 33(115), 319-323.

Jacobel, R.W. and R.A. Bindschadler, 1993. Radar studies in the mouths of Icc Streams D and F, Antarctica. Ann. Glaciol, 17, $262-268$.

Jacobel, R.W., S. K. Anderson, and D.F. Rioux, 1988. A portable digital data-acquisition systcm for surface-based ice-radar studies. 7. Glaciol, 34, 118, 349-354.

Jacobel, R.W., K. E. Nelson and R. A. Bindschadler. 1992. Radar studies of ice thickness and surface features at the mouths of Ice Strcams D and E, Antarctica. Antarc. J. U.S., 27, 47-49.

MacAyeal, D. R. 1984. Numerical simulations of the Ross Sea tides. 7. Geophys. Res., 89(CI), 607-6I5.

Smith, A.M., 1991. The use of tiltmeters to study the dynamics of Antarctic ice-shelf grounding lines. 7. Glaciol., 37 (125), 51-58.

Whillans, I, M. and R. B. Alley. 1991. Changes in the West Antarctic ice sheet. Science, 254(5034), 959-963.

The accuracy of references in the text and in this list is the responsibility of the authors, to whom queries should be addressed. 